\title{
Decision-making framework for the application of in-situ activated carbon amendment to sediment
}

\section{Yongju Choi ${ }^{a}$, Yeo-Myoung Cho ${ }^{b}$, William R. Gala ${ }^{c}$, Thomas P. Hoelen ${ }^{\mathrm{c}}$, David}

Wernerd $^{d}$, Richard G. Luthy ${ }^{b, *}$

aapartment of Civil and Environmental Engineering, Seoul National University, Seoul 151-744, South Korea

bepartment of Civil and Environmental Engineering, Stanford University, Stanford, California 94305-4020, United States

${ }^{\mathrm{c} C h e v r o n ~ E n e r g y ~ T e c h n o l o g y ~ C o m p a n y, ~ S a n ~ R a m o n, ~ C a l i f o r n i a ~ 94583-2324, ~ U n i t e d ~}$

States

${ }^{\mathrm{d}}$ School of Civil Engineering and Geosciences, Newcastle University, Newcastle upon Tyne, NE1 7RU, United Kingdom

* Corresponding author. Tel.: +1 650721 2615; fax: +1 650725 9720; E-mail address: luthy@stanford.edu (R. G. Luthy).

Postal address: Room 191, Yang \& Yamazaki Environment \& Energy Building, 473 Via Ortega, Stanford, California 94305-4020, USA 


\begin{abstract}
This study provides a decision-support framework and a design methodology for preliminary evaluation of field application of in-situ activated carbon (AC) amendment to sediment to control the (bio)availability of hydrophobic organic contaminants. The decision-making framework comprises four sequential steps: screening assessment, input parameter determination, model prediction, and evaluation for process optimization. The framework allows the application of state-of-the-art experimental and modeling techniques to assess the effectiveness of the treatment under different field conditions and is designed for application as a part of a feasibility study. Through a stepwise process it is possible to assess the effectiveness of in-situ AC amendment with a proper consideration of different site conditions and application scenarios possible in the field. The methodology incorporates the effect of various parameters on performance including: site-specific kinetic coefficients, varied AC dose and particle size, sediment and AC sorption parameters, and pore-water velocity. The modeling framework allows comparison of design alternatives for treatment optimization and estimation of long-term effectiveness over a period of 10-20 years under slow mass transfer in the field.
\end{abstract}

Keywords: activated carbon; decision-support; in-situ treatment; sediment; feasibility study 


\section{Introduction}

In-situ activated carbon (AC) amendment is a new technology for the treatment of hydrophobic organic contaminants (HOCs) in sediments. The technique is expected to grow in acceptance as a treatment option because there is a strong need for an in-place, cost-effective, and non-destructive sediment management approach as an alternative or adjunct to dredging or capping [1]. Since the first laboratory demonstration by Zimmerman et al. [2], researchers in the U.S. and Europe have successfully proven the effectiveness of the technology to reduce HOC equilibrium aqueous concentration, uptake by benthic invertebrates, and flux into the water column for various groups of compounds including polychlorinated biphenyls (PCBs), polycyclic aromatic hydrocarbons (PAHs), and organochlorine pesticides [3-12]. Successful pilot-scale studies have been conducted at several sites in the U.S. and Norway with varied site conditions and modes of application [13-18].

While the laboratory studies and field trials are encouraging, they also revealed that the effectiveness of the treatment is somewhat variable from site to site depending on the properties of the target contaminant, site conditions, and engineering options applied for the treatment $[13-16,18]$. Also of concern is the long-term effectiveness of the amendment, as to date the field performance of $\mathrm{AC}$ in pilot studies has been monitored for no more than five years [16]. Rather than removing contaminants from the site, the AC treatment targets the reduction of the (bio)availability of the contaminants that exist in sediment. Therefore, it is important to verify that the contaminants sequestered by $\mathrm{AC}$ will not be released back to the sediment or pore-water and become available to aquatic organisms in the long term. Monitoring results to date suggest that $\mathrm{AC}$ performance 
continues to improve with time in accord with mass transfer models (Cho et al., 2012, Choi et al., 2014a)

In the field, AC can be delivered to the sediment in either of two modes: mechanical mixing of $\mathrm{AC}$ into sediment or applying $\mathrm{AC}$ as a thin-layer. For mechanical mixing, a device is employed to mix the AC into the biologically active layer of sediment (e.g., 15-30 cm) to reduce the bioavailability of HOCs in sediment to benthic organisms and to diminish the likelihood of AC being transported off-site by waves or currents [14, 18]. For thin-layer AC application, AC is spread onto the contaminated sediment with the expectation that the bioturbation action by benthic organisms will eventually mix AC into the sediment [15]. The expected benefit of thin-layer AC application is the reduction of HOC flux to the water column in the short term and the reduction of HOC bioavailability to benthic organisms in the long term after significant bioturbation activity.

This study focuses on an assessment framework for mechanical mixing of AC with sediment as a delivery method because of the current knowledge and accumulated experience for this method of deployment compared to a thin-layer AC application. This knowledge provides a more robust database for the modeling and experimental approaches employed in the assessment framework. The framework may also be applicable to thin-layer applications if significant AC mixing occurs by bioturbation after thin-layer capping of $\mathrm{AC}$ and if the $\mathrm{AC}$ distribution pattern and mixing depth resulting from the bioturbation can be characterized.

To date, various studies have been conducted to improve the mechanistic understanding of in-situ AC amendment and to evaluate the effectiveness of the treatment for different situations. Laboratory studies [2-4, 6, 8, 19-21] characterized the effects of 
compound properties, site-specific properties, and various engineering options on the effectiveness of AC amendment. Building on these laboratory observations and theoretical analyses, an HOC mass transfer model was developed to predict the effectiveness of in-situ AC amendment [9, 16, 22, 23]. This model was shown to provide reasonable estimate of treatment effectiveness for a pilot-scale study on PCB-impacted sediments [16]. Using results from 24-month column studies in the laboratory, the model adequately described the effects of contaminant properties, site sediment properties, and AC dose and particle size [23].

Hence given the experience in the last decade, it is timely to incorporate the stateof-the-art modeling and experimental tools in a framework that enables an engineering assessment of the short- and long-term effectiveness of the treatment technique in the field. This aids decisions as to whether in-situ AC amendment is a valid treatment option that offers an efficient and cost-effective treatment of HOCs in sediments when site conditions are favorable for its application.

In this paper, a decision-making framework for the assessment of in-situ AC amendment is presented to apply the current level of scientific knowledge to evaluate the feasibility of the treatment. The content of the framework includes preparation, execution, and utilization of the HOC mass transfer model to quantitatively predict the short- and long-term effectiveness of the treatment under different site conditions and practical engineering options. The framework is designed for use during a feasibility study to enable consideration of in-situ AC amendment in comparison with other treatment options. 


\section{Requirements for the assessment framework}

The framework for the site-specific assessment of in-situ AC amendment assumes that the site has been adequately characterized to determine remedial objectives. To support the assessment framework proposed here, the site characterization should address the questions shown in Table 1 and the answers to the questions should correspond to the conditions described therein.

Table 1. Questions to be addressed in the steps prior to the assessment of in-situ AC amendment and the corresponding conditions for the assessment to be valid.

\begin{tabular}{l|l}
\hline Questions to be addressed & Conditions for the assessment to be valid \\
\hline $\begin{array}{l}\text { What compounds in the site sediment } \\
\text { are driving the risk? }\end{array}$ & $\begin{array}{l}\text { The major risk drivers should be hydrophobic } \\
\text { organic compounds }\left(\log K_{o w}>3\right) .\end{array}$ \\
\hline $\begin{array}{l}\text { What indicator will be used to } \\
\text { measure the success of the treatment? }\end{array}$ & $\begin{array}{l}\text { The treatment effectiveness is quantified either } \\
\text { by sediment pore-water concentration, benthic } \\
\text { organism concentration, or the model-derived } \\
\text { effective sediment concentration. }\end{array}$ \\
\hline $\begin{array}{l}\text { For the indicator selected, what are } \\
\text { the current level and cleanup goal? }\end{array}$ & $\begin{array}{l}\text { Specific values for the current level and cleanup } \\
\text { goal are established for the site that the in-situ } \\
\text { AC amendment is going to be applied. Data for } \\
\text { the current level are obtained not only for gross } \\
\text { sum of an HOC group but also for individual } \\
\text { members. }\end{array}$ \\
\hline
\end{tabular}

The primary risk-driving sediment contaminants should be hydrophobic organic compounds (HOCs; $\log \mathrm{K}_{\mathrm{ow}}>3$ ). The experimental and modeling procedures for the framework have been developed using HOCs such as PAHs, PCBs, and DDT (dichlorodiphenyltrichloroethane) as target contaminants. For relatively less hydrophobic compounds, the validity of the assessment results obtained following the framework would need to be evaluated with additional testing. 
The objective of in-situ AC amendment is to reduce (bio)availability of contaminants in sediment, which results in reduced contaminant risk to aquatic biota and humans. As contaminants are not physically removed from the sediment, there is no change in the bulk sediment concentration following AC deployment and a measure of the treatment effectiveness should not be based on absolute contaminant concentration in sediment. For the proposed assessment, it is most convenient to use the sediment porewater concentration as an indicator of AC performance. Sediment pore-water concentrations have been used most frequently to quantify the effectiveness of $\mathrm{AC}$ treatment in pilot studies, laboratory experiments, and numerical modeling $[2,4,14,16$, $18,22,23]$. HOC accumulation in representative benthic organisms is an appropriate indicator as well, and is a direct measure of HOC bioavailability. Finally, the success of treatment can be defined on the basis of the modeled "effective" sediment HOC concentration (i.e., sediment HOC concentration in the sediment-phase only, excluding HOCs sorbed to AC). HOCs sorbed to AC exhibit substantially less bioavailability than those associated with sediment $[10,24]$. Therefore, the modeled reduction in the effective sediment concentration indicates the reduction in contaminant bioavailability and thus, the effectiveness of the AC amendment. The limitation of using effective sediment concentration as an indicator is that the actual values cannot be directly measured in the field.

For this assessment framework, it is important that the site be characterized and a numerical cleanup target be defined using the selected effectiveness indicator. If the level of contamination is reported as the sum of similarly-structured HOCs (e.g., $\sum$ PAHs, $\sum$ PCBs, and $\sum$ DDTs), data for individual HOCs should be evaluated to identify key 
chemicals that can potentially be used as representative compounds for the modeling portion of the assessment.

As with other sediment remedial options, the proposed assessment framework is valid when off-site contaminant sources are properly controlled such that the contaminated sediment itself is the major source of contamination. The model employed for the current assessment does not account for the influx of contaminants after AC deployment. Nonetheless, recent studies suggest that AC deployed in the field can deal with low-level incoming contaminants when there is sufficient bioturbation activity [25].

\section{Framework for the site-specific assessment}

The framework developed in this study for site-specific assessment for field application of in-situ AC amendment is shown in Fig. 1. Four sequential steps are proposed: screening assessment, input parameter determination, model prediction, and process optimization. These steps may be applied in a feasibility study (in terms of the U.S. EPA Superfund cleanup process), or equivalent, at a remedial site to assess the effectiveness of in-situ AC amendment compared to other remedial alternatives. These steps are intended to support the assessments and decision-making processes related to the treatment effectiveness. A feasibility study or any such processes should account for factors such as implementability, cost, and government and public acceptance in addition to the treatment effectiveness [26]. Table A.1 in Appendix A suggests which phase of the U.S. EPA Superfund cleanup process the four steps of the framework could be applied. 
Fig. 1. Framework for the site-specific assessment for field application of in-situ AC amendment.

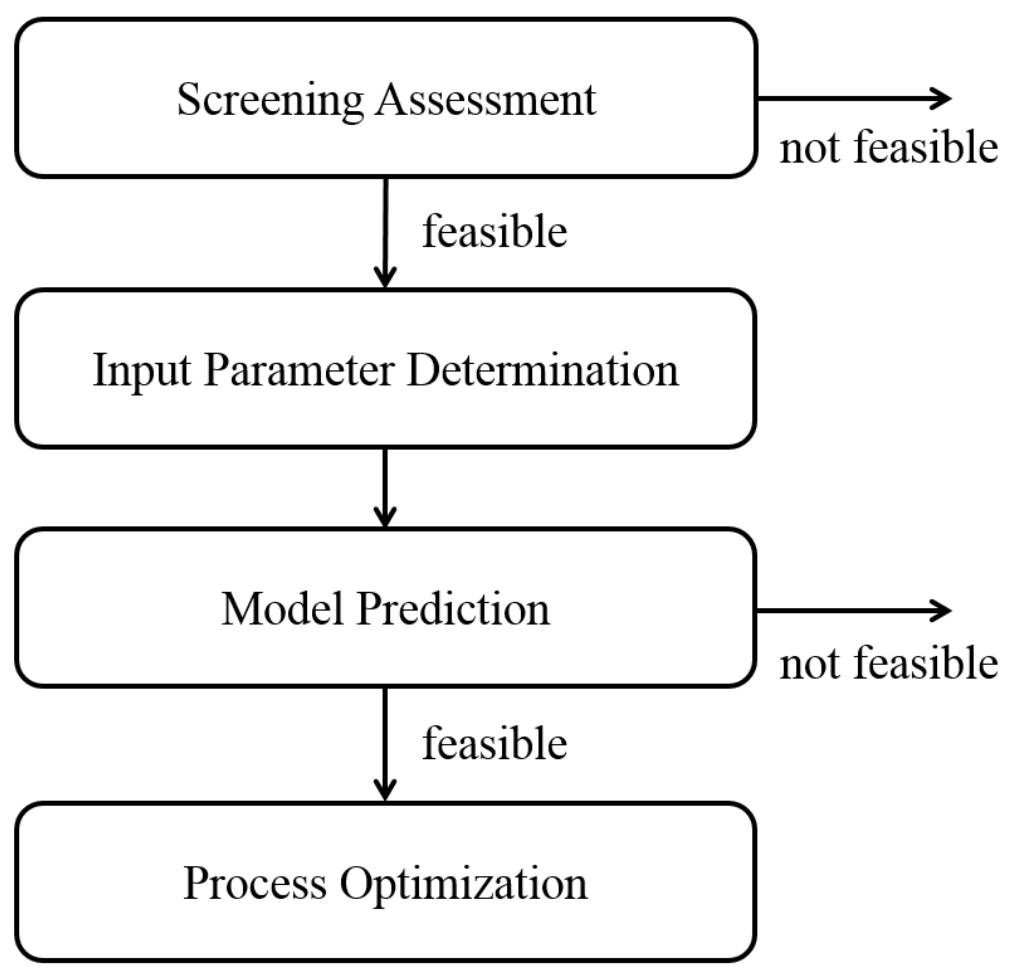

The framework employs a two-level approach for the feasibility assessment of $i n-$ situ AC amendment. A laboratory screening assessment allows a quick (within several months for sampling, testing, and data analysis) and efficient way to qualitatively test whether AC amendment will be beneficial. Next, site-specific physicochemical properties related to the performance of the treatment are determined. Using the site-specific properties as input parameters, a state-of-the-art HOC mass transfer model is applied in the model prediction step to quantitatively estimate the effectiveness of the treatment over time. The last step comprises process optimization considerations and uses the HOC mass transfer model to assess engineering variables for preliminary design. 


\section{1. $\quad$ Screening assessment}

The screening assessment is a relatively short-term laboratory study (2-3 months including test preparation, execution, and analysis) to obtain an initial indication of the feasibility of $\mathrm{AC}$ amendment. It allows a relatively rapid and inexpensive screening-level decision of whether AC treatment will show effectiveness for the study site. Factors that affect the performance include whether: the major risk drivers in the sediment are highly hydrophobic $\left(\log K_{o w}>6\right)$ such that the sediment desorption and AC uptake kinetics are very slow; the contaminants in sediments have undergone significant weathering resulting in very slow sediment desorption kinetics; or the sediment is highly impacted (more than $5 \%$ by sediment dry weight) by non-aqueous phase liquids (NAPLs) or tarlike materials that may interfere with HOC sorption to AC. Laboratory screening tests would indicate if these factors are likely to affect the in-situ AC amendment.

For the screening assessment, a slurry-phase test is conducted using representative sediment samples collected in the field. The results of the slurry-phase test account for the effects of the interplay of HOC physicochemical properties, HOC partitioning characteristics, and AC sorption and sediment desorption characteristics on the effectiveness of $\mathrm{AC}$ amendment, which cannot otherwise be assessed by simple means [27]. Details on the proposed test conditions and procedures are described in Appendix A. The sediment is either treated or untreated with a certain dose of AC for a month or two under continuous mixing and the final aqueous HOC concentrations are analyzed. AC 
amendment may be considered feasible if the treatment efficiency observed in the laboratory, as shown below, is greater than $70 \%$ :

$$
\text { Observed treatment efficiency }(\%)=C_{w, \text { treated }} / C_{w, \text { untreated }} \times 100
$$

where $C_{w, \text { treated }}$ and $C_{w \text {,untreated }}$ are the aqueous contaminant concentrations of target HOCs $\left(\mathrm{g} \mathrm{cm}^{-3}\right)$ in AC-treated and untreated slurries, respectively. Studies with successful demonstration of AC amendment in pilot-scale studies or sediment columns showed $70 \%$ to $>99 \%$ treatment efficiency in slurry-phase laboratory tests $[2,3,18,19]$.

\subsection{Input parameter determination}

The goal of the input parameter determination is to determine site-specific physicochemical parameter values required for an HOC mass transfer model to quantitatively predict the effectiveness of in-situ $\mathrm{AC}$ amendment.

The input parameters required for the model are listed in Table 2. Parameters such as mixing depth, and $\mathrm{AC}$ dose and particle size define the engineering application of the AC amendment, which are determined prior to the input parameter determination or used as variables to optimize the treatment. Densities and porosities of sediment and AC, and aqueous diffusivities are obtained easily or default values can be used otherwise. Variations of sediment particle density and porosity, and aqueous diffusivity within a plausible range in the field have been shown not to significantly affect the HOC mass transfer modeling results [22]. Sediment concentrations for target HOCs may be determined during the remedial investigation. 
Table 2. List of input parameters for the HOC mass transfer model.

\begin{tabular}{|c|c|c|c|c|}
\hline Parameter & Unit & Symbol & Source & $\begin{array}{l}\text { Default } \\
\text { value }\end{array}$ \\
\hline initial mechanical mixing period & $\min$ & $t_{\operatorname{mix}}$ & engineered & 1 \\
\hline $\begin{array}{l}\text { AC-sediment contact in stagnant } \\
\text { mode (post-treatment monitoring } \\
\text { period) }\end{array}$ & month & $t_{\text {unmix }}$ & predetermined & - \\
\hline nominal mixing depth & $\mathrm{cm}$ & $z$ mix & engineered & 15 or 30 \\
\hline sediment inter-particle porosity & - & $N$ & $\begin{array}{l}\text { measured or } \\
\text { default value used }\end{array}$ & 0.5 \\
\hline sediment intra-particle porosity & - & $p_{s}$ & $\begin{array}{l}\text { measured or } \\
\text { default value used }\end{array}$ & 0.1 \\
\hline sediment particle density & $\mathrm{g} \mathrm{cm}^{-3}$ & $d_{s}$ & $\begin{array}{l}\text { measured or } \\
\text { default value used }\end{array}$ & 2.3 \\
\hline pore-water flow velocity & $\mathrm{cm} \mathrm{d}^{-1}$ & $u_{s z}$ & $\begin{array}{l}\text { measured or } \\
\text { default value used }\end{array}$ & 0 \\
\hline AC dose & $\mathrm{g} \mathrm{g}^{-1}$ & dose $_{A C}$ & engineered & - \\
\hline $\begin{array}{l}\text { AC particle radius (geometric } \\
\text { mean of } 0.5 \mathrm{x} \text { lower and upper } \\
\text { particle size limit) }\end{array}$ & $\mathrm{cm}$ & $r_{A C}$ & engineered & - \\
\hline AC particle density & $\mathrm{g} \mathrm{cm}^{-3}$ & $d_{A C}$ & $\begin{array}{l}\text { measured or } \\
\text { provided by } \\
\text { manufacturer }\end{array}$ & - \\
\hline AC intra-particle porosity & $\mathrm{g} \mathrm{cm}^{-3}$ & $p_{A C}$ & measured & . \\
\hline initial sediment concentration & $\mathrm{g} \mathrm{cm}^{-3}$ & $C_{\text {sedo }}$ & measured & - \\
\hline diffusion coefficient in water & $\mathrm{cm}^{2} \mathrm{~s}^{-1}$ & $D_{w}$ & literature & - \\
\hline $\begin{array}{l}\text { sediment-water partition } \\
\text { coefficient } \\
\text { fast-HOC-release rate from } \\
\text { sediment }\end{array}$ & $\begin{array}{l}\mathrm{cm}^{3} \mathrm{~g}^{-1} \\
\mathrm{~s}^{-1}\end{array}$ & $\begin{array}{l}K_{d} \\
k_{\text {fast }}\end{array}$ & $\begin{array}{l}\text { measured or } \\
\text { calculated } \\
\text { measured }\end{array}$ & - \\
\hline $\begin{array}{l}\text { slow-HOC-release rate from } \\
\text { sediment }\end{array}$ & $\mathrm{s}^{-1}$ & $k_{\text {slow }}$ & measured & - \\
\hline $\begin{array}{l}\text { fraction of slow-HOC-releasing } \\
\text { sediment }\end{array}$ & - & $f_{\text {slow }}$ & measured & - \\
\hline $\begin{array}{l}\text { apparent AC-water partition } \\
\text { coefficient }\end{array}$ & $\mathrm{cm}^{3} \mathrm{~g}^{-1}$ & $K_{A C, a p p}$ & $\begin{array}{l}\text { measured or } \\
\text { calculated }\end{array}$ & - \\
\hline $\begin{array}{l}\text { apparent AC intra-particle } \\
\text { diffusion coefficient }\end{array}$ & $\mathrm{cm}^{2} \mathrm{~s}^{-1}$ & $D_{A C, a p p}$ & $\begin{array}{l}\text { measured or } \\
\text { calculated }\end{array}$ & - \\
\hline $\begin{array}{l}\text { longitudinal dispersivity (in } \\
\text { presence of pore-water } \\
\text { movement) }\end{array}$ & $\mathrm{cm}$ & $\alpha_{z}$ & $\begin{array}{l}\text { measured or } \\
\text { default value used }\end{array}$ & 0.1 \\
\hline
\end{tabular}


Laboratory experiments or field measurements may be used to determine parameters including those describing mass transfer processes for sediment and AC, and pore-water movement and dispersion. Because some of these parameters are highly dependent on site conditions [19,23], obtaining site-specific values enhances the accuracy of the model prediction. The suggested site-specific model input parameter requirements are summarized in Table $\mathbf{3}$ with detailed discussions provided in Appendix A. These values are not regularly measured during a remedial investigation.

Table 3. Site-specific determination requirements for the input parameters for the HOC mass transfer model.

\begin{tabular}{|c|c|c|}
\hline Properties & Parameters & Site-specific determination of parameters \\
\hline $\begin{array}{l}\text { Sediment HOC release } \\
\text { kinetics }\end{array}$ & $\begin{array}{l}k_{\text {fast }}, k_{\text {slow }}, \\
f_{\text {fast }} f_{\text {slow }}\end{array}$ & $\begin{array}{l}\text { Required. Desorption parameters are strongly site- } \\
\text { specific and have a significant effect on AC } \\
\text { performance. The parameters should be determined } \\
\text { by laboratory sediment desorption experiments. }\end{array}$ \\
\hline $\begin{array}{l}\text { Sediment-water HOC } \\
\text { partitioning }\end{array}$ & $K_{d}$ & $\begin{array}{l}\text { Recommended. The } K_{d} \text { value can be determined by a } \\
\text { sediment-water equilibrium test. Otherwise, it can be } \\
\text { determined by sediment and aqueous equilibrium } \\
\text { concentrations if pre-determined values are available. } \\
\text { For non-historical contamination sites with little black } \\
\text { carbonaceous matter, a regression model can be used } \\
\text { instead. }\end{array}$ \\
\hline \multirow[t]{2}{*}{$\begin{array}{l}\text { AC HOC sorption } \\
\text { characteristics }\end{array}$} & $K_{A C, a p p}$ & $\begin{array}{l}\text { Recommended. The } K_{A C, a p p} \text { value can be determined } \\
\text { by a laboratory experiment using HOC-preloaded } \\
\text { passive sampling devices. Literature values or } \\
\text { regression models are available for absolute AC } \\
\text { partition coefficients for single solutes in clean water } \\
\left(K_{A C, a b s}\right) \text {, but the apparent value }\left(K_{A C, a p p}\right) \text { may be a } \\
\text { factor of } 2 \text { to } 100 \text { smaller than the } K_{A C, a b s} \text { value } \\
\text { because of competition among different members of } \\
\text { HOCs. }\end{array}$ \\
\hline & $D_{A C, a p p}$ & $\begin{array}{l}\text { Optional. The } D_{A C, a p p} \text { value can be determined either } \\
\text { by a regression model }[22,28] \text { or by a combination of } \\
\text { laboratory experiments and an HOC mass transfer } \\
\text { model. }\end{array}$ \\
\hline
\end{tabular}




\begin{tabular}{lll}
\hline $\begin{array}{l}\text { Hydrodynamic } \\
\text { conditions }\end{array}$ & $v_{s z}, \alpha_{z}$ & $\begin{array}{l}\text { Optional. } \text { Pore-water movement is not a significant } \\
\text { factor in cohesive sediments, where application of AC } \\
\text { amendment is feasible. For relatively high pore-water }\end{array}$ \\
& flow regions (e.g., $>20 \mathrm{~cm} \mathrm{~d}^{-1}$ as Darcy's velocity), \\
& pore-water flow may be determined in-situ [29] and \\
& incorporated in the mass transfer model for better \\
& prediction of effectiveness. \\
\hline
\end{tabular}

The HOCs of concern in sediment are often defined as a group of compounds that may comprise several species (e.g., DDT and its metabolites) to more than a thousand different individual species (e.g., petroleum-derived alkylated PAHs). As the model parameter determination and the modeling itself cannot be done for all species of the compound group in most cases, several model compounds should be selected for this purpose. For the model compounds to be representative of the HOCs of concern at the site, they should be i) among the chemicals with highest abundance and greatest toxicity or risk, and ii) representative of the range of mass transfer properties for the target HOCs. After the model compounds are chosen, laboratory experiments and a literature survey are performed to determine the model input parameters as shown in Table 3. Methods to determine each model input parameter are described in detail in Appendix A.

\subsection{Model prediction}

In the model prediction step, the effectiveness of in-situ AC amendment is quantitatively predicted for the target compounds over the possible post-treatment monitoring period using an HOC mass transfer model described in this section. The simulation results are compared with the cleanup goal to finally determine the feasibility of the treatment. 


\subsubsection{HOC mass transfer model overview}

The concept and assumptions of the HOC mass transfer model are described elsewhere [9, $16,23]$. The model developed by previous efforts $[9,16,22,23,27]$ to improve the applicability to field application of in-situ AC amendment is further modified in this study to include different mechanical mixing scenarios. A comprehensive discussion on the validity and limitation of the model, and sensitivity of modeling results to input parameters is provided in Appendix A.

The model is comprised of a continuous-mixing module to simulate the HOC mass transfer during $\mathrm{AC}$ deployment (i.e., mechanical mixing) and a no-mixing module for the state when the AC-mixed sediment is quiescent for the remaining duration of the remediation project period. Each stage of the HOC mass transfer mechanism in the ACamended sediment is simulated by the model including: i) the diffusive mass transfer within the sediment and AC particles, ii) the exchange of HOCs among the particulate phases and pore-water, and iii) the HOC movement through the pore-water by molecular diffusion, mechanical dispersion, and pore-water advection.

In mathematical terms, the intraparticle diffusion of an $\mathrm{HOC}$ within a particle phase $i$ is expressed by Fick's second law of diffusion in spherical coordinates [22, 28]:

$$
\frac{\partial u_{i}}{\partial \tau_{i}}=\frac{\partial^{2} u_{i}}{\partial x_{i}{ }^{2}}
$$

with two boundary conditions

$$
\begin{aligned}
& u_{i}\left(x_{i}=0\right)=0 \\
& u_{i}\left(x_{i}=1\right)=\left[\left(1-p_{i}\right) \rho_{s, i} K_{i}+p_{i}\right] C_{w}
\end{aligned}
$$

where $x_{i}$ is the non-dimensional distance from the spherical center $\left(=r_{i} / R_{i} ; r_{i}\right.$ is the distance $[\mathrm{cm}]$ from the center and $R_{i}$ is the particle radius [cm]); $\tau_{i}$ is the non-dimensional 
time $\left(=D_{a p p, i} \cdot t / R_{i}^{2} ; D_{a p p, i}\right.$ is the apparent diffusion coefficient $\left[\mathrm{cm}^{2} \mathrm{~s}^{-1}\right]$ within a particle phase $i$ and $t$ is the time $[\mathrm{s}]) ; u_{i}\left(=x_{i} \cdot S_{i}\right)$ is the variable for local HOC concentration in a particle where $S_{i}$ is the volumetric HOC concentration $\left[\mathrm{ng} \mathrm{cm}^{-3}\right] ; p_{i}$ is the intra-particle porosity $[-] ; \rho_{s, i}$ is the solid density $\left[\mathrm{g} \mathrm{cm}^{-3}\right] ; K_{i}$ is the HOC partition coefficient $\left[\mathrm{cm}^{3} \mathrm{~g}^{-1}\right]$; and $C_{w}$ is the pore-water HOC concentration. Eq. (4) states that the surface of the particles are equilibrated with the surrounding water with respect to HOC sorption. The HOC pore-water concentration in each well-mixed unit is calculated by a HOC mass balance equation with advection and hydrodynamic dispersion terms $[9,23]$

$$
\frac{\partial C_{w}}{\partial t}=-v_{s z} \frac{\partial C_{w}}{\partial z}+\left(D_{x} \frac{\partial^{2} C_{w}}{\partial x^{2}}+D_{y} \frac{\partial^{2} C_{w}}{\partial y^{2}}+D_{z} \frac{\partial^{2} C_{w}}{\partial z^{2}}\right)-\sum_{i}\left(\frac{V_{i}}{V_{w}} \cdot \frac{\partial S_{a v g, i}}{\partial t}\right)
$$

where $v_{s z}$ is the pore-water seepage velocity in z-dir $\left[\mathrm{cm} \mathrm{s}^{-1}\right] ; D_{x}, D_{y}$, and $D_{z}$ are the hydrodynamic dispersion coefficients $\left[\mathrm{cm}^{2} \mathrm{~s}^{-1}\right]$ in $\mathrm{x}-, \mathrm{y}-$, and z-dir, respectively; $V_{i}$ is the volume of a particle phase $i(=$ sediment or $\mathrm{AC})\left[\mathrm{cm}^{3}\right] ; V_{w}$ is the water volume $\left[\mathrm{cm}^{3}\right] ; S_{a v g, i}$ is the average volumetric $\mathrm{HOC}$ concentration $\left[\mathrm{ng} \mathrm{cm}^{-3}\right]$ in a particle phase $i$ in the corresponding well-mixed unit. Eqs. (2)-(5) are solved numerically in the HOC mass transfer model to track the HOC mass transfer processes with given initial conditions and model system configurations.

For the continuous-mixing module, the entire model system is treated as a single well-mixed unit possessing a uniform pore-water concentration and a uniform intraparticle concentration profile for the particulate phases. For the no-mixing module, the system is constructed as a three-dimensional structure comprising a stack of cubes with a depth determined by a nominal mixing depth of AC treatment (usually $15-30 \mathrm{~cm}$ ). The width and length of the model system are minimized ( $10 \times 10$ cubes) to reduce computation time assuming that the AC treatment is horizontally invariable. Model runs 
can be repeated with different conditions if there is interest in assessing any significant horizontal variations. The side length of the model cubes is determined according to the AC particle size as described in detail in Appendix A. Each model cube has two sediment domains and a pore-water phase. The two sediment domains are the fast- and slow-HOC-releasing domains according to the HOC desorption kinetics. Each model cube is treated to be well-mixed.

An AC particle is assigned to some of the cubes according to the characteristic AC distribution. To apply different mixing scenarios of mechanical mixing between AC and sediment, the HOC mass transfer model is revised in this study to accommodate two types of AC distribution heterogeneity: depth dependent and millimeter-scale [27]. For the "heterogeneous" case of the depth-dependent heterogeneity, the mixing depth is divided into halves, and a greater $\mathrm{AC}$ dose is assigned to the upper half of the mixing depth than the lower half for the case when the mechanical mixing is not complete over the whole mixing depth. For the "heterogeneous" case of millimeter-scale heterogeneity, it is assumed that the AC doses in 2-mm subsections of each half of the mixing depth vary within $50 \%$ standard deviation. These AC distribution scenarios are based on the AC dose analysis at a pilot-scale study site at Hunters Point Shipyard, CA, USA reported in Choi et al. [27]. In contrast to the heterogeneous AC distribution scenarios, the "homogeneous" option assumes identical AC dose throughout, both at the large and small scales. This results in four possible mixing scenarios (see Appendix A). AC distribution heterogeneity at a scale smaller than a millimeter does not affect the AC performance after more than a year after AC deployment [23]. For the model prediction step, the authors recommend heterogeneous AC distributions for both types of heterogeneity to 
provide a conservative estimate. Detailed discussion on the $\mathrm{AC}$ distribution schemes for the two scales is found in Appendix A.

The HOC mass transfer model is prepared as a standalone program with source code written in MATLAB $^{\circledR}$ and a graphical user interface for data input and output. The source files for the standalone model are provided in Appendices B and C.

\subsubsection{Model execution}

Prior to the model run, engineering parameters such as AC dose and particle size are determined for a case used in the model prediction step. AC dose for simulation may be determined as 1-2 times sediment TOC content with an upper limit of about 5-10\% on sediment dry weight basis. The upper and lower size limits for AC particles are recommended as between 10 to $500 \mu \mathrm{m}$ with a specific range determined by commercial availability.

The model is run to simulate the duration of a post-treatment monitoring period, e.g., 20 years. The simulation results are collected at every minute for the initial mechanical mixing period and every 24 hours for the no mixing period. Three model output data are obtained: the average pore-water concentration $\left(\mathrm{ng} \mathrm{cm}^{-3}\right)$, the average effective sediment concentration (ng g ${ }^{-1}$; i.e., concentration of HOCs associated with sediment particles), and the average AC concentrations (ng $\left.\mathrm{g}^{-1}\right)$ for target HOCs.

\subsubsection{Analysis of modeling results}

The modeling results are compared with the cleanup goal to determine the feasibility of in-situ AC amendment. The modeling results are obtained for two or three specific target 
compounds while, for most cases, the cleanup goal is given for gross sum of a target contaminant group (e.g., total PAH or PCB concentrations). To be conservative, the AC amendment is judged to be feasible if the target treatment efficiency, defined as the treatment efficiency required for the cleanup goal, is achieved for all model compounds. In other words, from the modeling results, the $\mathrm{AC}$ treatment is feasible if

$$
\left[\frac{I_{t=t_{f}}^{j}}{I_{t=0}^{j}}\right]_{\text {model }}<\left[\frac{I_{\text {cleanup }}^{\text {sum }}}{I_{\text {initial }}^{\text {sum }}}\right]_{\text {field }}=\text { Target treatment efficiency }
$$

(for all $j$ )

where $I$ is the value of the indicator to define the current state of contamination and the remediation goal for a target compound $j$ (for modeling) or for the sum of all target compounds (in the field), and $t_{f}$ is the maximally allowable post-monitoring period. As described in section 2, the indicator can be either HOC sediment pore-water concentration, the effective sediment concentration, or accumulation in a target organism. The modeling results can be directly applied to Eq. (6) for HOC sediment pore-water concentration and the effective sediment concentration. For HOC accumulation in a target organism, a biodynamic modeling approach $[10,30]$ may be employed in conjunction with the HOC mass transfer model. The biological uptake model described in Appendix A allows calculation of biota HOC concentration from the simulated HOC concentrations in pore-water, sediment, and AC.

Fig. 2 shows example results for a former pilot-scale study site for AC amendment at Hunters Point Shipyard, California, USA [13, 23]. The results are obtained in the current work using the modified HOC mass transfer model and the model input parameters given in Table A.2 in Appendix A. The modeling is conducted for PCB 153 and 180, which are representative congeners for hexa- and hepta-chlorinated biphenyls 
that are major constituents of PCBs in the study sediment [4]. The modeling results in Fig. 2 show that the treatment satisfies the cleanup goal 8 years after the AC deployment when pore-water concentration is used as an indicator and 10 years when the effective sediment concentration is used. For both cases, PCB 180 determines the time to reach the cleanup goals as it responds slower to the AC treatment than PCB 153.

Fig. 2. Example model prediction for Hunters Point Shipyard (California, USA) site. The simulated AC application scenario is 3 dry wt $\%$ AC dose, 75-150 $\mu \mathrm{m} \mathrm{AC}$ particle size, and heterogeneous depth-dependent and mm-scale AC distribution. The assessment example is illustrated (a) for pore-water concentration with an arbitrary cleanup goal of $90 \%$ reduction from an initial level $\left(\left[I_{\text {cleanup }}^{\text {sum }} / I_{\text {initial }}^{\text {sum }}\right]_{\text {field }}=\right.$ 0.1) and (b) for effective sediment concentration with the cleanup goal ( $I_{\text {cleanup }}^{\text {sum }}$ of $1.24 \mathrm{mg} \mathrm{kg}^{-1}$ and the maximum sediment concentration ( $\left.I_{\text {initial }}^{\text {sum }}\right)$ of $7 \mathrm{mg} \mathrm{kg}^{-1}$ as total PCBs determined in the site feasibility study [31].

(a)
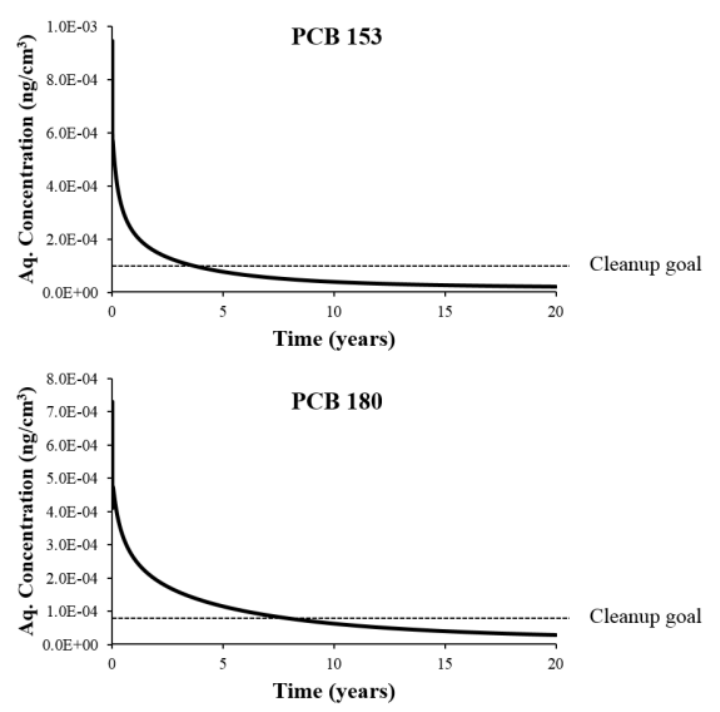

(b)
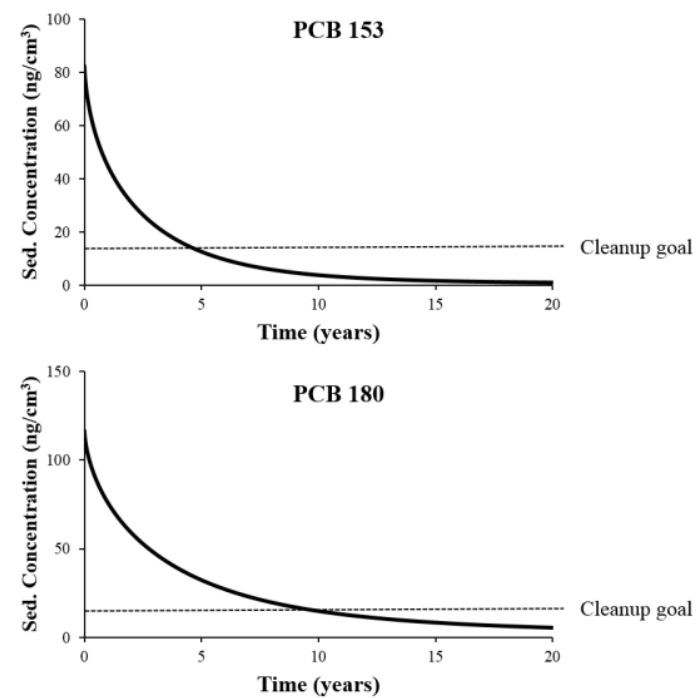


\subsection{Process optimization}

The HOC mass transfer model can assess performance sensitivity to engineering design choices of AC dose, AC particle size, and mixing intensity. The modeling results for different combinations of those parameters obtained in the current study using the modified HOC mass transfer model are illustrated in Fig. $\mathbf{3}$ as an example. An arbitrary cleanup goal of $90 \%$ reduction in PCB pore water concentration is achieved in approximately 2 to 13 years depending on AC dose, size and distribution in sediment. Other factors to consider in process design are the cost, environmental soundness and engineering feasibility.

Fig. 3. Modeling results for Hunters Point Shipyard (California, USA) site. Three possible AC application scenarios are compared for PCB congener 180. Case 1: 3 dry wt \% AC dose, 75-150 $\mu \mathrm{m}$ AC particle size, and heterogeneous depth-dependent and homogeneous mm-scale AC distribution; Case 2: 3\% AC dose, 150-300 $\mu \mathrm{m}$ AC particle size, and homogeneous depth-dependent and mm-scale AC distribution; Case 3: 2\% AC dose, 32-75 $\mu \mathrm{m}$ AC particle size, heterogeneous depth-dependent and mm-scale AC distribution. 


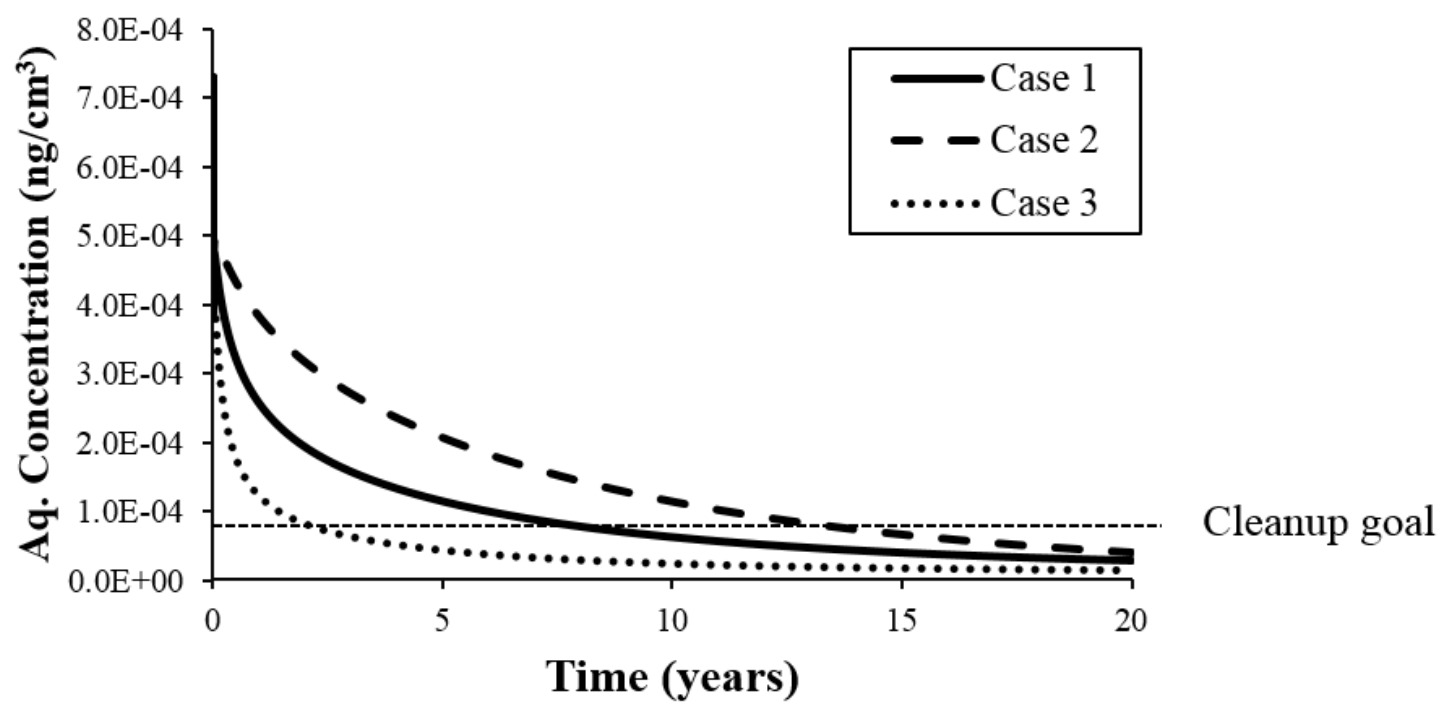

Larger AC doses result in better treatment efficiency (see Fig. A.1 in Appendix A) but are more costly and cause greater alteration of the field sediment. The benefit of $\mathrm{AC}$ amendment for reduction in HOC bioavailability is achieved faster for a smaller AC particle size (Fig. A.2 in Appendix A) but there should be practical constraints and health concerns such as difficulty in handling, potential dispersion of AC particles into the air, and greater potential of particle loss from the sediment [19]. The potential ecotoxicological effects by AC amendment to sediment need to be considered when determining $\mathrm{AC}$ dosing and $\mathrm{AC}$ particle size. The extent of ecotoxicological effects by $\mathrm{AC}$ amendment is still uncertain with some studies reporting no effect and some showing a response [32]. However, studies reporting a distinct observation of adverse effects find that those effects are more pronounced at high AC doses and smaller AC grain size [3234]. Therefore, regarding any potential adverse effects on benthic organisms, smaller AC doses and larger AC grain sizes would be desirable. Based on the laboratory studies and field observations reported to date $[14,15,32,34,35]$ the authors recommend 5-10\% 
(sediment dry weight basis) AC dose and $75 \mu \mathrm{m} \mathrm{AC} \mathrm{particle} \mathrm{size} \mathrm{(lower} \mathrm{limit)} \mathrm{as} \mathrm{cut-off}$ values for full-scale field application. When pilot-scale studies are implemented prior to full-scale application, results of field observations of ecological conditions can be used to determine whether larger AC doses and smaller particle sizes may be employed.

More uniform AC distribution within sediment by intensive mechanical mixing speeds up the treatment (as depicted in Fig. A.3 in Appendix A), but is more costly and may cause greater disturbance on the site ecosystem. However, there is still limited information on what characteristic AC distribution would result from specific mixing activities in the field. The options provided in this work, homogeneous or heterogeneous depth-dependent and millimeter-scale AC distribution, may be used as a reference rather than a definitive scenario for field application. The AC distribution following mechanical mixing needs to be monitored in the field. A preliminary demonstration with a fieldmixing device may be conducted and the observed AC distribution applied with the HOC mass transfer model for improved simulation results.

\section{Additional considerations}

The framework presented in this study provides a well-defined, state-of-the-art method for site-specific assessments of the effectiveness of in-situ AC amendment. The framework allows quick screening of the feasibility of the treatment, long-term and sitespecific prediction of the effectiveness, and optimization of the engineering variables that need to be determined for the treatment.

The main tool for the quantitative assessment of feasibility employed in the suggested framework is the HOC mass transfer model, which was validated by previous 
studies using field and laboratory data for various HOCs in sediments having different characteristics $[9,16,19,22,23,27]$. Some potentially important factors are not fully addressed by the current model because of i) computational loading of the model, ii) limited quantitative knowledge of the process, and/or iii) relatively insignificant effects observed in model validation studies. Discussion of these factors including bioturbation by benthic organisms, sediment deposition, and an influx of contaminants and dissolved organic matter (DOM) is provided in Appendix A. If such processes are occurring significantly in the field, a pilot-scale demonstration would be needed prior to largerscale application of in-situ AC amendment to validate the performance predicted by the HOC mass transfer model.

Beyond the scope of this framework, which focuses on the effectiveness of the insitu AC amendment to reduce the (bio)availability of HOCs in sediments, there are additional factors that should be considered for the field application of the technique. These include, but are not limited to, the effect of the treatment on aquatic ecosystem health, engineering feasibility, AC stability, and monitoring methods. Although not discussed here, socioeconomic factors involved in the remediation project should also be taken into account for the selection and optimization of the treatment.

Possible adverse effect of in-situ AC amendment on benthic ecosystem health should be considered for the remedial design of the technique, as discussed in the previous section when determining AC dose and particle size. In addition, pre- and posttreatment monitoring plans are needed to verify that the actual implementation of the technique does not adversely affect the benthic ecosystem health in the field. The monitoring plans should account for seasonal and spatial variability. 
The engineering feasibility of the remedial action often determines the mode of application for in-situ AC amendment. As mentioned above, two modes of application for AC delivery are possible: mechanical mixing of AC into sediment and thin-layer AC application. The mechanical mixing has an advantage over the thin-layer application in that it reduces the bioavailability of HOCs to a larger depth, which may include the entire biologically active zone in sediment and may result in less impact on benthic community health because of the relatively smaller local AC dose in the AC-amended layer $[14,15]$. Water fencing and pumping may be needed prior to $\mathrm{AC}$ mixing in shallow regions or intertidal areas. In deeper water, areas that are difficult to access such as under wharfs, or sensitive ecosystems such as tidal marshes, thin-layer AC application approaches should be considered. Currently available thin-layer AC application techniques include application of either AC only or AC-clay mixture onto sediment, and spreading pelletized AC should be considered $[1,15,36]$.

The AC-amended sediment should be physically stable to achieve the benefit of $\mathrm{AC}$ in the long term. In other words, the AC should remain in place after application so that it can continuously sequester HOCs that are slowly released from sediment. The sediment cohesiveness and maximum shear stress at the site are key factors that govern the physical stability of AC [37]. AC properties (e.g., particle size) and mode of application (AC mechanical mixing or thin-layer capping, and the presence of supporting media in case of thin-layer capping) are also important factors for AC stability [15, 37]. If needed, laboratory experiments and hydrodynamic modeling should be conducted to ensure that the maximum shear stress does not exceed the critical shear stress of ACamended sediment at the site, as shown in Zimmerman et al. [37]. 
Appropriate field monitoring methods should be selected to investigate whether the application of in-situ AC amendment is successful. The methodology and schedule to monitor contaminant (bio)availability, ecosystem health, and AC stability should be determined and pre-treatment monitoring should be conducted prior to the application. The equilibrium pore-water HOC concentrations or contaminant flux to water, which are frequently used as a measure of contaminant availability, can be determined by in-situ passive sampling techniques developed by several researchers [38-40]. In-situ and ex-situ bioaccumulation studies using indigenous species may also be conducted as a direct measure of contaminant bioavailability. The AC dose should be monitored over time to ensure that the AC remains in place after the application. Benthic community surveys may be needed to investigate the effect of the treatment on ecosystem health. Because onsite measurements of contaminant (bio)availability and benthic community are subject to site conditions, e.g., seasonal variation [14], the pre- and post-treatment monitoring should be carefully scheduled to ensure that any significant changes after the treatment are not masked by natural variability.

\section{Conclusions}

A framework for the site-specific assessment of the effectiveness of in-situ AC amendment is developed with detailed guidance for each stage of the framework. By following the framework and the guidance, one can apply the state-of-the-art experimental and modeling tools to assess the short- and long-term effectiveness of the treatment for a given site. As with any new environmental technology, follow-up work is needed to develop standard protocols to practically apply the guidelines provided in this 
study. The framework is expected to serve a key role in a feasibility study designed to assess whether in-situ AC amendment is a viable remedial alternative. This will facilitate the possible adoption of the technology to efficiently and cost-effectively treat the HOCs in sediment where site conditions are favorable.

\section{Acknowledgements}

Funding for this research was provided by the Chevron Energy Technology Company (contract number: CW786669) and the Department of Defense Strategic Environmental Research and Development Program (SERDP), ER-1552. Yongju Choi would like to thank the Integrated Research Institute of Construction and Environmental Engineering (IRICEE) in the School of Engineering at Seoul National University for technical support. 


\section{REFERENCES}

[1] U. Ghosh, R.G. Luthy, G. Cornelissen, D. Werner, C.A. Menzie, In-situ sorbent amendments: a new direction in contaminated sediment management, Environ. Sci. Technol., 45 (2011) 1163-1168.

[2] J.R. Zimmerman, U. Ghosh, R.N. Millward, T.S. Bridges, R.G. Luthy, Addition of carbon sorbents to reduce PCB and PAH bioavailability in marine sediments: Physicochemical tests, Environ. Sci. Technol., 38 (2004) 5458-5464.

[3] J.R. Zimmerman, D. Werner, U. Ghosh, R.N. Millward, T.S. Bridges, R.G. Luthy, Effects of dose and particle size on activated carbon treatment to sequester polychlorinated biphenyls and polycyclic aromatic hydrocarbons in marine sediments, Environ. Toxicol. Chem., 24 (2005) 1594-1601.

[4] Y. Choi, Y.-M. Cho, R.G. Luthy, In situ sequestration of hydrophobic organic contaminants in sediments under stagnant contact with activated carbon. 1. Column studies, Environ. Sci. Technol., 48 (2014) 1835-1842.

[5] P.B. McLeod, M.J. Van den Heuvel-Greve, S.N. Luoma, R.G. Luthy, Biological uptake of polychlorinated biphenyls by Macoma balthica from sediment amended with activated carbon, Environ. Toxicol. Chem., 26 (2007) 980-987.

[6] J.E. Tomaszewski, D. Werner, R.G. Luthy, Activated carbon amendment as a treatment for residual DDT in sediment from a superfund site in San Francisco Bay, Richmond, California, USA, Environ. Toxicol. Chem., 26 (2007) 2143-2150. 
[7] X.L. Sun, U. Ghosh, PCB bioavailability control in Lumbriculus variegatus through different modes of activated carbon addition to sediments, Environ. Sci. Technol., 41 (2007) 4774-4780.

[8] S.E. Hale, J.E. Tomaszewski, R.G. Luthy, D. Werner, Sorption of dichlorodiphenyltrichloroethane (DDT) and its metabolites by activated carbon in clean water and sediment slurries, Water Res., 43 (2009) 4336-4346.

[9] S.E. Hale, D. Werner, Modeling the mass transfer of hydrophobic organic pollutants in briefly and continuously mixed sediment after amendment with activated carbon, Environ. Sci. Technol., 44 (2010) 3381-3387.

[10] E.M.-L. Janssen, M.N. Croteau, S.N. Luoma, R.G. Luthy, Measurement and modeling of polychlorinated biphenyl bioaccumulation from sediment for the marine polychaete neanthes arenaceodentata and response to sorbent amendment, Environ. Sci. Technol., 44 (2010) 2857-2863.

[11] R.N. Millward, T.S. Bridges, U. Ghosh, J.R. Zimmerman, R.G. Luthy, Addition of activated carbon to sediments to reduce PCB bioaccumulation by a polychaete (Neanthes arenaceodentata) and an amphipod (Leptocheirus plumulosus), Environ. Sci. Technol., 39 (2005) 2880-2887.

[12] R.C. Brandli, T. Hartnik, T. Henriksen, G. Cornelissen, Sorption of native polyaromatic hydrocarbons (PAH) to black carbon and amended activated carbon in soil, Chemosphere, 73 (2008) 1805-1810. 
[13] Y.-M. Cho, D.W. Smithenry, U. Ghosh, A.J. Kennedy, R.N. Millward, T.S. Bridges, R.G. Luthy, Field methods for amending marine sediment with activated carbon and assessing treatment effectiveness, Mar. Environ. Res., 64 (2007) 541-555.

[14] Y.-M. Cho, U. Ghosh, A.J. Kennedy, A. Grossman, G. Ray, J.E. Tomaszewski, D.W. Smithenry, T.S. Bridges, R.G. Luthy, Field application of activated carbon amendment for in-situ stabilization of polychlorinated biphenyls in marine sediment, Environ. Sci. Technol., 43 (2009) 3815-3823.

[15] G. Cornelissen, M.E. Krusa, G.D. Breedveld, E. Eek, A.M.P. Oen, H.P.H. Arp, C. Raymond, G. Samuelsson, J.E. Hedman, O. Stokland, J.S. Gunnarsson, Remediation of contaminated marine sediment using thin-layer capping with activated carbon-a field experiment in Trondheim Harbor, Norway, Environ. Sci. Technol., 45 (2011) 6110-6116.

[16] Y.-M. Cho, D. Werner, Y. Choi, R.G. Luthy, Long-term monitoring and modeling of the mass transfer of polychlorinated biphenyls in sediment following pilot-scale in-situ amendment with activated carbon, J. Contam. Hydrol., 129-130 (2012) 25-37.

[17] C.R. Patmont, U. Ghosh, P. LaRosa, C.A. Menzie, R.G. Luthy, M.S. Greenberg, G. Cornelissen, E. Eek, J. Collins, J. Hull, T. Hjartland, E. Glaza, J. Bleiler, J. Quadrini, In situ sediment treatment using activated carbon: A demonstrated sediment cleanup technology, Integr. Environ. Assess. Manag., 11 (2015) 195-207.

[18] B. Beckingham, U. Ghosh, Field-scale reduction of PCB bioavailability with activated carbon amendment to river sediments, Environ. Sci. Technol., 45 (2011) 1056710574. 
[19] Y. Choi, Y.-M. Cho, W.R. Gala, R.G. Luthy, Measurement and modeling of activated carbon performance for the sequestration of parent- and alkylated-polycyclic aromatic hydrocarbons in petroleum-impacted sediments, Environ. Sci. Technol., 47 (2013) 1024-1032.

[20] X. Sun, U. Ghosh, The effect of activated carbon on partitioning, desorption, and biouptake of native polychlorinated biphenyls in four freshwater sediments, Environ. Toxicol. Chem., 27 (2008) 2287-2295.

[21] D. Werner, C.P. Higgins, R.G. Luthy, The sequestration of PCBs in Lake Hartwell sediment with activated carbon, Water Res., 39 (2005) 2105-2113.

[22] D. Werner, U. Ghosh, R.G. Luthy, Modeling polychlorinated biphenyl mass transfer after amendment of contaminated sediment with activated carbon, Environ. Sci. Technol., 40 (2006) 4211-4218.

[23] Y. Choi, Y.-M. Cho, D. Werner, R.G. Luthy, In situ sequestration of hydrophobic organic contaminants in sediments under stagnant contact with activated carbon. 2. mass transfer modeling, Environ. Sci. Technol., 48 (2014) 1843-1850.

[24] P.B. McLeod, M.J. Van Den Heuvel-Greve, R.M. Allen-King, S.N. Luoma, R.G. Luthy, Effects of particulate carbonaceous matter on the bioavailability of benzo[a]pyrene and 2,2 ',5,5'-tetrachlorobiphenyl to the clam, Macoma balthica, Environ. Sci. Technol., 38 (2004) 4549-4556. 
[25] D. Lin, Y.-M. Cho, D. Werner, R.G. Luthy, Bioturbation delays attenuation of DDT by clean sediment cap but promotes sequestration by thin-layered activated carbon, Environ. Sci. Technol., 48 (2014) 1175-1183.

[26] USEPA, The U.S. EPA Superfund cleanup process, http://www.epa.gov/superfund/cleanup/, accessed in Jul 2014.

[27] Y. Choi, Y.-M. Cho, R.G. Luthy, D. Werner, Predicted effectiveness of in-situ activated carbon amendment for field sediment sites with variable site- and compoundspecific characteristics, J. Hazard. Mater., 301 (2016) 424-432.

[28] S.-C. Wu, P.M. Gschwend, Numerical modeling of sorption kinetics of organic compounds to soil and sediment properties, Water Resour. Res., 24 (1988) 1373-1383.

[29] Y.-M. Cho, D. Werner, K.B. Moffett, R.G. Luthy, Assessment of advective porewater movement affecting mass transfer of hydrophobic organic contaminants in marine intertidal sediment, Environ. Sci. Technol., 44 (2010) 5842-5848.

[30] S.N. Luoma, P.S. Rainbow, Why is metal bioaccumulation so variable? Biodynamics as a unifying concept, Environ. Sci. Technol., 39 (2005) 1921-1931.

[31] Barajas \& Associates, Inc., Final Feasibility Study Report for Parcel F. Hunters Point Shipyard, San Francisco, California, 2008.

[32] E.M.-L. Janssen, B.A. Beckingham, Biological responses to activated carbon amendments in sediment remediation, Environ. Sci. Technol., 47 (2013) 7595-7607. 
[33] M.T. Jonker, M.P. Suijkerbuijk, H. Schmitt, T.L. Sinnige, Ecotoxicological effects of activated carbon addition to sediments, Environ. Sci. Technol., 43 (2009) 5959-5966.

[34] D. Kupryianchyk, E.P. Reichman, M.I. Rakowska, E.T.H.M. Peeters, J.T.C.

Grotenhuis, A.A. Koelmans, Ecotoxicological effects of activated carbon amendments on macroinvertebrates in nonpolluted and polluted sediments, Environ. Sci. Technol., 45 (2011) 8567-8574.

[35] E.M.-L. Janssen, Y. Choi, R.G. Luthy, Assessment of nontoxic, secondary effects of sorbent amendment to sediments on the deposit-feeding organism Neanthes arenaceodentata, Environ. Sci. Technol., 46 (2012) 4134-4141.

[36] M.I. Rakowska, D. Kupryianchyk, J. Harmsen, T. Grotenhuis, A.A. Koelmans, In situ remediation of contaminated sediments using carbonaceous materials, Environ. Toxicol. Chem., 31 (2012) 693-704.

[37] J.R. Zimmerman, J.D. Bricker, C. Jones, P.J. Dacunto, R.L. Street, R.G. Luthy, The stability of marine sediments at a tidal basin in San Francisco Bay amended with activated carbon for sequestration of organic contaminants Water Res., 42 (2008) 50725072.

[38] J.E. Tomaszewski, R.G. Luthy, Field deployment of polyethylene devices to measure PCB concentrations in pore water of contaminated sediment, Environ. Sci. Technol., 42 (2008) 6086-6091. 
[39] L.A. Fernandez, J.K. MacFarlane, A.P. Tcaciuc, P.M. Gschwend, Measurement of freely dissolved PAH concentrations in sediment beds using passive sampling with lowdensity polyethylene strips, Environ. Sci. Technol., 43 (2009) 1430-1436.

[40] E. Eek, G. Cornelissen, G.D. Breedveld, Field measurement of diffusional mass transfer of HOCs at the sediment-water interface, Environ. Sci. Technol., 44 (2010) 6752-6759. 


\section{Screening Assessment}

\section{feasible}

\section{Input Parameter Determination}

\section{not feasible}

\section{Model Prediction}

feasible 